\title{
Subjective wellbeing of Italian healthcare professionals during the SARS-CoV-2 outbreak: A quasi-experiment
}

\author{
Matteo Makowiecki · Valentina Ungaretti · Marta Arzilli \\ Leonardo Urbani · Matteo Cecchi · Michela Maielli · Sergio Ardis
}

\begin{abstract}
Italy was one of the strongest hit countries from the SARS-CoV-2 and the healthcare system was put under exceptional stress during the outbreak. The lockdown imposed on the population put the economy on hold and opened the way for a crisis that would have an impact on the healthcare system and the economy of the country. This study compares levels of subjective wellbeing among healthcare professionals before the outbreak and during the most critical moment of the lockdown, when Italy was the first country in the world by number of infections. Subjective wellbeing was measured with emotional wellbeing, job satisfaction, global happiness and satisfaction with life. Each measure was compared before and during the outbreak as well as among different subgroups of respondents. A special attention was put on inequalities in professional level, gender and educational level as well as their effect on subjective wellbeing. The study finds that while emotional wellbeing had a slight decrease, other measures were untouched and job satisfaction even increased during the lockdown period. Present wellbeing differences based in inequalities in professional and educational level were lifted once professionals were fighting the SARS-CoV-2 outbreak. This decrease in inequalities and increase in job satisfaction might be strongly related to a newfound trust in healthcare professionals, a high gratitude from the population and a feeling of accomplishment and meaning as described in the PERMA model. The findings of this study should help healthcare organizations to keep inequalities low as well as other organizations to apply those learnings in their structure.
\end{abstract}

Keywords: Healthcare workers, subjective wellbeing, job satisfaction, SARS-CoV-2

Matteo Makowiecki Italian Society for Health Promotion matteomakowiecki@gmail.com

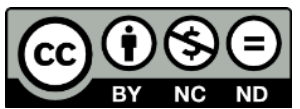




\section{Practice implications}

This study was undertaken during a difficult time for healthcare systems around the world, which at the same time provided unprecedented possibilities to explore different dimensions of subjective wellbeing for healthcare professionals and their changes during a health crisis. The findings that were obtained by comparing different subgroups of professionals can help both healthcare and other organisations in implementing ad-hoc programmes and policies to keep higher wellbeing and lower inequalities.

First, we see that the level of job satisfaction for lower hierarchical positions in the hospital (that also have a lower income) reached the same level as the one of managers during the pandemic. This is due to the higher level of gratitude expressed by the population and leads us to advise any kind of organization to increase gratitude at all levels to have an equal job satisfaction. This can be done by fostering a tendency for gratitude to all members (Sheldon \& Lyubomirsky, 2006) as well as by gratitude journaling and random acts of kindness (Stegen \& Wankier, 2018).

Second, female professionals faced a higher decrease in emotional wellbeing because of a stronger increase in negative affects. The introduction of positive psychology in the workplace with effective interventions could mitigate the effect of negative affects and provide a general increase in the emotional wellbeing of the mostly hit individuals (Kaplan et al., 2014).

Third, governments should base their policies to overcome the pandemic not only on GDP and economic indicators, but on different measures of wellbeing (Adler \& Seligman, 2016). In particular, this study shows how an increased meaning and accomplishment in one's work can lead to a higher wellbeing even during economic crises. The same can be said about positive emotions and positive relationships inside and outside of organizations, which can increase satisfaction with life and mitigate the effect of negative events.

\section{Introduction}

On February 22nd, 2020, the first infection of SARS-CoV-2 was reported in the North of Italy and the outbreak spread without control in the following days. By March $8^{\text {th }}$, the number of confirmed cases was 7.375 with 366 deaths. On this date, the first measure to limit the diffusion of the virus was approved by the government. Nevertheless, it was a matter of weeks before Italy became the first country in the world by number of positive cases and deaths.

On March 23rd, the number of confirmed cases was 63.927 with 6.077 deaths and 7.432 recovered patients. On this day, a new measure ordered to stop production activities and the movement of people in the whole country with the exception of essential services. The Italian economy was put on hold and the resulting drop in trade volumes gave start to an economic crisis that would follow the health crisis and businesses - forced to stop their activities for more than two months, started to fear insolvency in case no state aid was provided.

Several researchers have prospected a negative impact on wellbeing and mental health (Montemurro, 2020; Pappa et al., 2020) because of this unexpected crisis. However, media and society were looking positively at the role of healthcare professionals, showing gratitude in the form of articles depicting doctors and nurses as heroes as well as providing gifts to hospital personnel. To assess whether the outbreak indeed had an effect on the subjective wellbeing of healthcare professional and of what kind, we decided to identify a reliable model to measure subjective wellbeing and apply it to our two data sets.

Given that we collected data on the wellbeing of healthcare professionals for a study of the Italian Society for Health Promotion (SIPS) and we were collecting similar data in the outbreak period for some master theses, we decided to compare the two data sets for this study. A 
comparison of wellbeing in two timeframes gave us the possibility to assess how wellbeing has changed during the lockdown and how it affected present inequalities between healthcare personnel.

\section{Literature review}

The topic of subjective wellbeing has been thoroughly studied in the past decades and researchers were able to find out which demographic factors affect ones' wellbeing (Wilson, 1967) as well as how wellbeing can increase because of individual and psychological factors (Diener et al., 1999).

Subjective Wellbeing is also proposed by Stiglitz et al. (2009) as an alternative measurement of quality of life, to take into account other factors than income. In particular, measurements of subjective wellbeing should take into account the meaning and personal goal of people, the presence of inequalities as well as the presence of positive emotions and the absence of negative emotions.

A model to measure wellbeing was provided by Seligman (2011) in his Flourish work. According to his PERMA model, subjective wellbeing depends on five elements that contribute to one's wellbeing, are pursued independently and can be defined and measured independently (Khaw \& Kern, 2015). Those elements are:

Positive emotions: happiness, pleasure and comfort.

Engagement: feeling of connection or interest in a given activity, organization or cause.

Relationships: Feelings of integration in society and of having an own social network.

Meaning: having a purpose in life and that gives the feeling of working for something bigger than the self.

Accomplishment: actual progress in the work towards one's goals.

Measurements of the PERMA model include the PERMA-Profiler (Kern \& Butler, 2016), which measures PERMA items and additional variables with a questionnaire composed of 15 plus eight items. In our study we measured positive and negative emotions as well as job satisfaction, which implies purpose on the job and can be connected to meaning (Watanabe et al., 2018).

Relationships in Italy have been studied by several researchers who found out that Italian regions present high levels of social capital and low inequalities in income and health (Sabatini, 2014). Those factors lead to high levels of subjective wellbeing.

The relationship between inequalities and wellbeing is still disputed and researchers documented contrasting results (Schneider, 2016). One interesting distinction is that while high inequalities negatively affect wellbeing in Western societies, those have a positive link in Asian and South American countries. The presence of inequalities in income and gender is proven to lead to higher wellbeing in individuals who accept and justify those inequalities, while wellbeing is lower in individuals with a more egalitarian view who are exposed to those inequalities (Napier et al., 2010; Napier \& Jost, 2008)

\section{Methodology}

\section{Measures}

The study was designed as cross-sectional and realized through an online survey that was repeated twice. The first survey was completed in 2018 and we assumed this time to represent the basic condition in the healthcare population. The second survey was completed in 2020 during the peak of the SARS-CoV-2 outbreak. The qualification of each participant was collected by asking a multiple-choice question inclusive of all professions foreseen by the Italian national educational accreditation system. Each participant was also asked for the beginning year of his 
healthcare occupation as well as birth year, gender, Italian region of residence and highest degree obtained.

Subjective well-being was measured with the scales recommended by the OECD (2013), translated and adapted in Italian by the SIPS (Ardis, 2014. [The promotion of wellbeing. Measures for its evaluation]). The scales that we measured are: emotional wellbeing (EW), global happiness $(\mathrm{GH})$ and satisfaction with life (SwL).

The first scale is composed of 10 items and evaluates emotional wellbeing (EW) experienced on the day before the survey's completion. Each item is evaluated on a Likert scale that goes from 0 , indicating the emotion was not experienced, to 10 , indicating that the emotion was experienced for the whole time. The average of items with a positive connotation (enjoyment, calm, happy, "did you laugh a lot yesterday?") represents the value for positive affect (PA). The average of items with negative connotation (worried, sadness, depressed, anger, stress, tired) represents the value for negative affect (NA). Emotional wellbeing is calculated as the average between positive and negative affects, after the scale position was reversed for negative affects. The score for each of the three dimensions varies from 0 to 10. We calculated Cronbach's Alpha for the emotional wellbeing scale and got a value of 0,8639 in 2018 and 0,8307 in 2020, an acceptable value of internal coherence of the scale to perform a test. The second scale is single-item and measures global happiness $(\mathrm{GH})$ on a Likert scale from 0 ("no happy at all") to 10 ("completely happy"). The third scale measures satisfaction with life (SwL) on a Likert scale from 0 ("not satisfied at all") to 10 ("completely satisfied"), this measurement was adopted by ISTAT (the national statistical institute in Italy) for the annual satisfaction with life survey.

Job satisfaction (JS) was evaluated with a single item and the question "at the moment, how satisfied are you with your job?" on a Likert scale from 0 (not satisfied at all) to 10 (very satisfied). All questions were mandatory.

\section{Procedure}

Participants were contacted through various channels and ask to fill in an online form, for example by email for participants of an online course provided by SIPS in 2017. In the invitation, it was asked to forward the email to other healthcare professionals to obtain the snowball effect. The link was also shared on social media, making it not possible to assess the total number of people invited to the study. The first survey started on January 14th, 2018 and ended on May 29th, 2018. The second survey started on March 28th, 2020 and ended on April 27th. The form was completely anonymous and each participant was informed that sending the survey indicated a personal consent to participate in the study.

\section{Analysis}

Data was collected with JotForm ${ }^{\circledR}$, exported in an Excel ${ }^{\circledR}$ worksheet and analysed with Minitab 19®. Measures from the 2018 sample were compared with the 2020 sample to look for differences in wellbeing levels during a stressful event. For correlations, the Pearson coefficient was used and means comparisons were done with a t-test or ANOVA analysis depending on each case. The level of statistical significance was fixed at a value of $\mathrm{p} \leq 0.02$, as is usual in medicine studies in Italy.

\section{Population}

In 2018, 1047 answers were submitted (810 males and 237 females) while the respondents for 2020 were 616 (161 males and 455 females). The average age was of 45,9 years with a standard 
deviation of 11,7 in 2018 and of 46,1 with a standard deviation of 12,3 in 2020. This doesn't show a statistically significant difference.

We divided Italian regions into three macro-regions (North, Centre and South). The respondents were divided by macro-regions as follows: $31,14 \%$ in the Centre, $52,50 \%$ in the North and $26,36 \%$ in the South in 2018 and $61,36 \%$ in the Centre, $27,11 \%$ in the North and $11,53 \%$ in the South in 2020. The population was also divided into managers/directors (M) and regular employees (NM) based on the contract they have with the Italian public authority. In Italy hospitals are mostly public and owned by the Health Ministry, that also prepares contracts for healthcare professionals. The contract used for physicians, pharmacists and biologists is a manager contract that requires higher qualifications and offers a higher income. Nurses and technical staff, on the other hand, receive a regular contract with a lower salary. Managers/directors participating in the survey were 240 (22,92\%) in 2018 and $239(38,80 \%)$ in 2020.

Data was analysed by comparing demographics as well as answers between the 2018 survey (t0) and the 2020 survey (t1). An overview of the demographic characteristics of both samples can be found in Table 1 .

Table 1.

Demographic characteristics

\begin{tabular}{|c|c|c|c|c|}
\hline \multirow[t]{2}{*}{ Characteristic } & \multicolumn{2}{|c|}{ to } & \multicolumn{2}{|c|}{ t1 } \\
\hline & N. & $\%$ & N. & $\%$ \\
\hline \multicolumn{5}{|l|}{ Gender } \\
\hline Female & 810 & 77.4 & 455 & 73.9 \\
\hline Male & 237 & 22.6 & 161 & 26.1 \\
\hline \multicolumn{5}{|l|}{ Macro-region } \\
\hline North & 445 & 42,5 & 167 & 27,1 \\
\hline Centre & 326 & 31,1 & 378 & 61,4 \\
\hline South & 276 & 26,4 & 71 & 11,5 \\
\hline \multicolumn{5}{|l|}{ Professional level } \\
\hline Manager & 240 & 22,9 & 239 & 38,8 \\
\hline Non-manager & 807 & 77,1 & 377 & 61,2 \\
\hline \multicolumn{5}{|l|}{ Educational level } \\
\hline University degree & 851 & 81,3 & 515 & 83,6 \\
\hline No university degree & 196 & 18,7 & 101 & 16,4 \\
\hline \multicolumn{5}{|l|}{ Age } \\
\hline Mean (DS) Y & \multicolumn{2}{|c|}{$45,9(11,7)$} & \multicolumn{2}{|c|}{$46,1(12,3)$} \\
\hline \multicolumn{5}{|c|}{ Years of work experience } \\
\hline Mean (DS) Y & \multicolumn{2}{|c|}{$19,7(12,2)$} & \multicolumn{2}{|c|}{$19,2(12,7)$} \\
\hline Total & \multicolumn{2}{|c|}{1047} & \multicolumn{2}{|c|}{616} \\
\hline
\end{tabular}

Of the $\mathrm{t} 1$ population, 112 were working in a setting with SARS-CoV-2 patients while 504 were not. This represents a $18,18 \%$ of respondents being directly involved in treating patients affected 
by the virus. Age and years of work experience were not significantly different between the two groups.

\section{Results}

Of the variables we defined to measure subjective wellbeing, the ones that had a reduction in t1 were emotional wellbeing, which went from 5,65 to 5,26, and global happiness, which moved from 6,88 to 6,62 . The change in emotional wellbeing was mainly based in a reduction of positive affect from 5,77 to 5,26, while negative affect had no significant change in t1. The decrease in global happiness was low but statistically significant $(6,88$ to 6,62$)$. Satisfaction with life presented no statistically significant difference between $\mathrm{t} 0$ and $\mathrm{t} 1$ while job satisfaction showed an increase during the lockdown period t1 $(6,32$ to 6,69$)$.

\section{Table 2.}

Wellbeing dimensions in $\mathrm{t} 0$ and $\mathrm{t} 1$

\begin{tabular}{|lccc|}
\hline Variable & $\begin{array}{c}\text { Mean (SD) } \\
\text { t0 }\end{array}$ & $\begin{array}{c}\text { Mean (SD) } \\
\text { t1 }\end{array}$ & p-value \\
\hline EW & $5,65(1,74)$ & $5,26(1,74)$ & 0,000 \\
\hline PA & $5,77(2,00)$ & $5,19(2,19)$ & 0,000 \\
\hline NA & $4,47(2,14)$ & $4,66(2,17)$ & 0,080 \\
\hline JS & $6,32(2,41)$ & $6,69(2,28)$ & 0,002 \\
\hline SWL & $6,95(1,81)$ & $6,84(2,04)$ & 0,304 \\
\hline GH & $6,88(1,80)$ & $6,62(2,16)$ & 0,014 \\
\hline
\end{tabular}

No statistically significant differences were found when comparing t1 variables between the subgroup working mainly with patients affected by the virus and the subgroup working with other patients.

While comparing the relevant dimensions for managers and non-managers in $t 0$, no statistically significant differences were found in EW, PA, NA and SWL. JS and GH, on the other hand, were significantly lower in the NM subgroup. In t1, the measures with no difference between the two subgroups were EW, PA, NA, SWL and JS. The only dimension with lower values for the NM subgroup was GH. This means that in t0 there were inequalities between managers and non-managers for both GH and JS, while in t1 the inequality in JS was not present anymore. 
Table 3.

Comparison for managers and non-managers

\begin{tabular}{|c|c|c|c|}
\hline & $\mathbf{M}$ & NM & \\
\hline Variable & Mean (DS) & Mean (DS) & p-value \\
\hline EW t0 & $5,70(1,71)$ & $5,63(1,76)$ & 0,573 \\
\hline EW t1 & $5,35(1,68)$ & $5,21(1,77)$ & 0,326 \\
\hline PA t0 & $5,89(2,07)$ & $5,73(1,98)$ & 0,288 \\
\hline PA t1 & $5,18(2,03)$ & $5,20(2,29)$ & 0,907 \\
\hline NA t0 & $4,49(2,05)$ & $4,47(2,17)$ & 0,908 \\
\hline NA t1 & $4,48(2,09)$ & $4,78(2,21)$ & 0,090 \\
\hline JS t0 & $6,75(2,32)$ & $6,20(2,42)$ & 0,002 \\
\hline JS t1 & $6,78(2,10)$ & $6,63(2,40)$ & 0,410 \\
\hline SWL t0 & $7,15(1,83)$ & $6,89(1,80)$ & 0,055 \\
\hline SWL t1 & $7,06(1,81)$ & $6,71(2,17)$ & 0,028 \\
\hline $\mathrm{GH}$ t0 & $7,20(1,73)$ & $6,78(1,82)$ & 0,001 \\
\hline $\mathrm{GH}$ t1 & $6,89(1,97)$ & $6,45(2,25)$ & 0,012 \\
\hline
\end{tabular}

In Figure 1 it is possible to see how the levels of JS had a significant increase in the NM subgroup and moved from 6,20 to 6,63. There was no significant change in the M subgroup.

\section{Figure 1.}

Job satisfaction and professional level

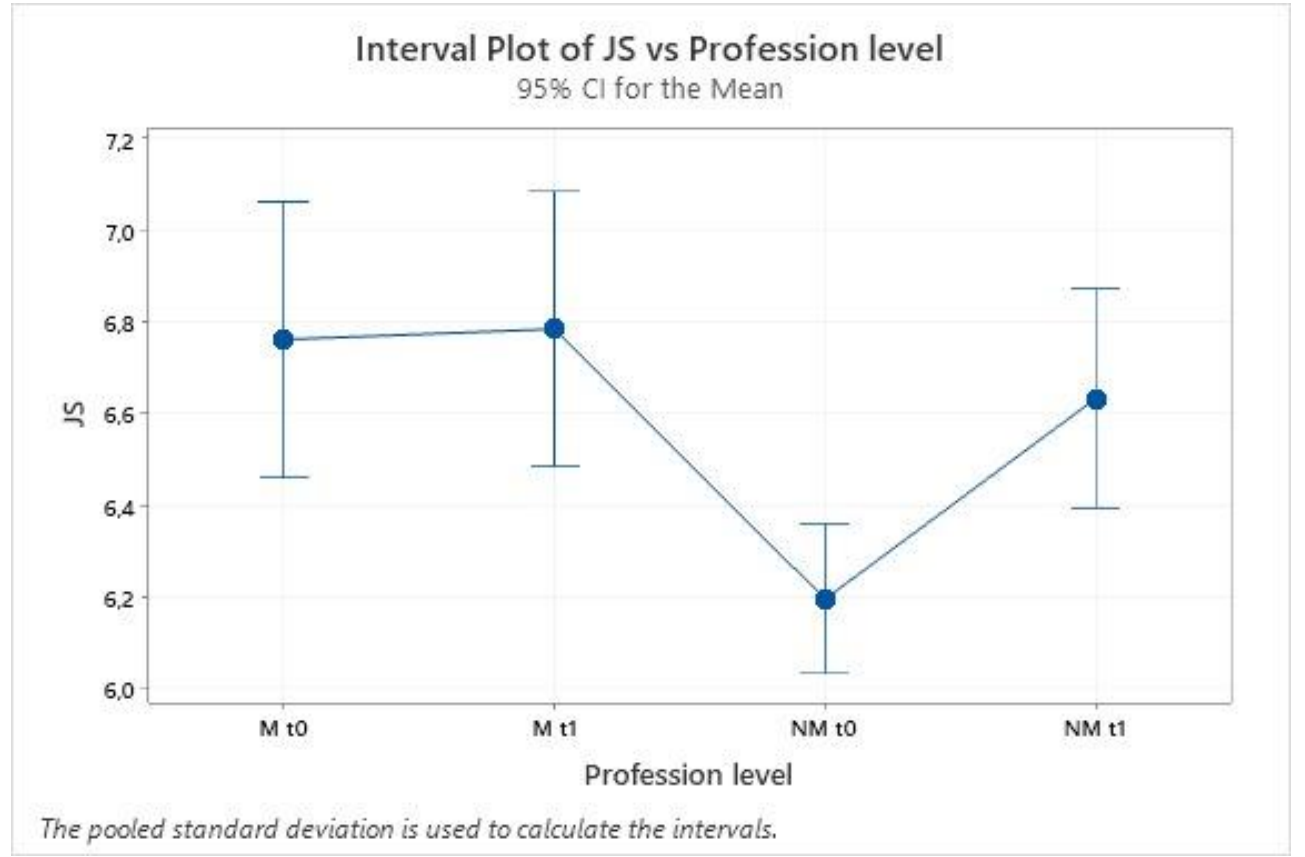

Comparison by gender

All measures were compared between male and female respondents. Females had a significantly lower level of EW, PA and JS in t0 compared to males. This difference was present during the 
virus outbreak as well. NA, SWL and GH showed no significant differences. As seen in Table 4, the difference in SWL became significant in $\mathrm{t} 1$ adding an additional difference between the subgroups.

Table 4.

Comparison between females and males

\begin{tabular}{|c|c|c|c|}
\hline & $\mathbf{F}$ & $\mathbf{M}$ & \\
\hline Variable & Mean (DS) & Mean (DS) & p-value \\
\hline EW t0 & $5,58(1,76)$ & $5,89(1,67)$ & 0,011 \\
\hline EW t1 & $5,14(1,75)$ & $5,61(1,64)$ & 0,002 \\
\hline PA t0 & $5,65(2,03)$ & $6,16(1,87)$ & 0,000 \\
\hline PA t1 & $5,01(2,23)$ & $5,70(2,00)$ & 0,000 \\
\hline NA to & $4,50(2,14)$ & $4,37(2,14)$ & 0,421 \\
\hline NA t1 & $4,73(2,22)$ & $4,48(1,99)$ & 0,184 \\
\hline JS t0 & $6,20(2,47)$ & $6,74(2,14)$ & 0,001 \\
\hline JS t1 & $6,52(2,37)$ & $7,18(1,95)$ & 0,001 \\
\hline SWL t0 & $6,89(1,83)$ & $7,15(1,74)$ & 0,046 \\
\hline SWL t1 & $6,71(2,13)$ & $7,23(1,73)$ & 0,002 \\
\hline GH t0 & $6,84(1,82)$ & $6,99(1,76)$ & 0,272 \\
\hline GH t1 & $6,53(2,23)$ & $6,87(1,94)$ & 0,071 \\
\hline
\end{tabular}

\section{Comparison by educational level}

All measures were compared between respondents with a university degree (A) and with no university degree (B). EW, PA and SWL were significantly lower in $t 0$ for professionals with a university degree. Other variables showed no significant differences. In t 1 the differences in EW and PA remained significant, while the difference in SWL was not significant anymore because of a decrease in the satisfaction with life of graduated professionals. 
Table 5.

Comparison by educational level

\begin{tabular}{|c|c|c|c|}
\hline & A & B & \\
\hline Variable & Mean (DS) & Mean (DS) & p-value \\
\hline EW t0 & $5,71(1,72)$ & $5,37(1,83)$ & 0,019 \\
\hline EW t1 & $5,35(1,74)$ & $4,82(1,66)$ & 0,004 \\
\hline PA t0 & $5,85(1,97)$ & $5,40(2,12)$ & 0,007 \\
\hline PA t1 & $5,32(2,16)$ & $4,52(2,23)$ & 0,001 \\
\hline NA t0 & $4,43(2,13)$ & $4,66(2,17)$ & 0,183 \\
\hline NA t1 & $4,62(2,17)$ & $4,89(2,15)$ & 0,257 \\
\hline JS t0 & $6,37(2,38)$ & $6,12(2,53)$ & 0,203 \\
\hline JS t1 & $6,70(2,28)$ & $6,61(2,32)$ & 0,718 \\
\hline SWL t0 & $7,02(1,74)$ & $6,62(2,06)$ & 0,012 \\
\hline SWL t1 & $6,93(1,97)$ & $6,39(2,34)$ & 0,029 \\
\hline $\mathrm{GH}$ t0 & $6,94(1,74)$ & $6,61(2,03)$ & 0,036 \\
\hline $\mathrm{GH}$ t1 & $6,71(2,12)$ & $6,15(2,30)$ & 0,024 \\
\hline
\end{tabular}

Comparison by age and work experience

Age of healthcare workers did not show a significant correlation with the dimensions examined, except for a low negative correlation with PA $(r h o=-0,104, p=0,009)$. Years of work experience showed no particular correlation with the dimensions of this study.

\section{Correlations}

As expected, all emotional wellbeing dimensions were positively correlated to each other with the exception of negative affect, which was negatively correlated with all other dimensions. This could be seen in both $\mathrm{t} 0$ and $\mathrm{t} 1$ and is represented in the tables below.

The $\mathrm{p}$-value was set to $\mathrm{p}<0,001$.

Table 6.

Correlations in $\mathrm{t} 0$

\begin{tabular}{|lrrrrr|}
\hline & EW t0 & PA t0 & NA t0 & JS t0 & SWL t0 \\
\hline PA t0 & 0,830 & & & & \\
\hline NA t0 & $-0,853$ & $-0,418$ & & & \\
\hline JS t0 & 0,538 & 0,500 & $-0,408$ & & \\
\hline SWL t0 & 0,609 & 0,636 & $-0,397$ & 0,591 & \\
\hline GH t0 & 0,626 & 0,641 & $-0,420$ & 0,606 & 0,751 \\
\hline
\end{tabular}


Table 7.

Correlations in $\mathrm{t} 1$

\begin{tabular}{|lrrrrr|}
\hline & EW t1 & PA t1 & NA t1 & JS t1 & SWL t1 \\
\hline PA t1 & 0,800 & & & & \\
\hline NA t1 & $-0,794$ & $-0,270$ & & & \\
\hline JS t1 & 0,435 & 0,490 & $-0,201$ & & \\
\hline SWL t1 & 0,472 & 0,569 & $-0,181$ & 0,655 & \\
\hline GH t1 & 0,582 & 0,633 & $-0,292$ & 0,620 & 0,711 \\
\hline
\end{tabular}

\section{Discussion}

Our study showed a slight decrease in emotional wellbeing and global happiness in the t1 group, but no significant change in satisfaction with life. The reason for this is that emotional wellbeing is influenced by positive and negative stimuli, while satisfaction with life represents a more stable type of cognitive wellbeing that is less influenced by external events (Luhmann et al., 2012).

The most evident and not obvious result of our study is an increase in job satisfaction during the lockdown, both for professionals working directly with SARS-CoV-2 patients and those who were not. Job satisfaction increased mostly in subjects with a lower professional level and indirectly a lower income. Because income stayed constant during the data collection period, those individuals might have found a higher meaning in their work or might have increased their job satisfaction because of an increased gratitude in their work. Gratitude is proven to increase wellbeing and lower negative emotions on the workplace (Di Fabio et al., 2017).

By dividing our data in different subgroups we could observe a lower level of emotional wellbeing in females and university graduates. This might be due to the fact that females are more sensitive to negative affect arising from problems at work and that university graduates fear their effort in getting a degree was not repaid with an adequate salary and work conditions. Job satisfaction increased in professionals with a non-manager contract while it had no change in managers. This might be due to an increase in respect and trust in healthcare professionals (Helliwell \& Wang, 2011).This increase was independent from hierarchical levels in the hospital and gave the feeling that each one's work is equally important.

In individuals with a university degree, a slight decrease in satisfaction with life was found and this took them on the same level as professionals without a university degree. This removed the inequality between individuals with and without a degree, although due to a decrease in one of the subgroups.

If we try to explain the changes in wellbeing for our sample with the PERMA-Model, we should notice that while in the whole population relationships, income and accomplishment could have decreased, healthcare workers could keep the same levels of income and relationships as well as higher feeling of accomplishment.

The attention for healthcare professionals in the media, which used to focus on the ineffectiveness of the state healthcare system and cases of mistakes in choosing treatments, switched to a completely new connotation showing those professionals as heroes fighting against a common enemy, and most newspapers used military vocabulary to describe this fight. According to Frey (2011), "war is happiness" in the sense that increased trust, friendship and collaboration in the fight, as well as a feeling of "combat flow", increase wellbeing of those 
involved. This can be a partial explanation of the increased wellbeing dimensions for healthcare professionals.

Based on our findings, we suggest future research to give more importance to the factors that increase wellbeing in pandemics as well as crises. A wellbeing study could be repeated after one year to measure whether job satisfaction maintained the increase that we found or whether it went back to pre-lockdown levels. Especially for healthcare workers, we find that these situations possibly increase some dimensions of wellbeing. This could be extended to other essential workers, or to professional groups that are particularly hit by other kinds of crises. Policy makers should take into account wellbeing indicators when defining their response, and healthcare workers should be supported by the government through additional monetary benefits and gratitude measures. This was already the case in Italy, where the government provided special bonuses to healthcare workers (after the data for this study was collected). However, those bonuses were contested by healthcare workers who didn't consider them as adequate to the additional effort they were making and the additional risk they were taking.

Among the limits of this study it is needed to mention that income was not measured directly but assumed based on the kind of employment contract that each professional had with the hospital and this allowed us to approximate an income difference. Wellbeing could also be influenced by other factors such as marital status and children, but we assumed those factors would not have a significant effect on our sample as it is relatively big for a study on wellbeing. However, this sample might be too small to represent the whole country.

\section{Conclusion}

The SARS-CoV-2 outbreak was an unprecedented event that impacted the lives of several people, not only in the healthcare sector. When countries like Italy went into a lockdown and hospitals started to face increasing numbers of patients, researchers were quick to assume healthcare workers' wellbeing would be strongly hit (Montemurro, 2020).

While stress and anxiety were indeed found increased in the first studies on the wellbeing of healthcare workers (Yuan et al., 2020), an increase in positive mood was also found.

When collecting data for the second period and seeing the general mood of people working in Italian hospitals, we were convinced the actual results would not be as obvious as thought. Our study allowed to partly contradict the general expectation for a decrease in wellbeing levels by exploring in detail how each dimension changed and by showing that most of them had no change while some even increased. With those findings it is possible to identify what increased wellbeing and preserve this effect as well as search deeper into factors decreasing wellbeing in a situation of crisis.

The effects on present inequalities gave us a feeling of decreasing inequalities and led us to suggest measures to maintain those effects in healthcare settings. The most interesting finding is that the effect of inequalities in professional levels and income on job satisfaction was mitigated by the increased gratitude and trust in all healthcare professions. This should be used as a basis to research how gratitude for the impact of one's job can be shown to other professional groups to remove the effects of income inequalities on a larger scale. The effects on wellbeing that we measured can also be used as a basis for public policies that also take into account non-economic factors (Adler \& Seligman, 2016).

\section{Authors}

Matteo Makowiecki

Italian Society for Health Promotion (SIPS) 
matteomakowiecki@gmail.com

Valentina Ungaretti

Independent researcher

Marta Arzilli

University of Pisa

Leonardo Urbani

University of Pisa

Matteo Cecchi

University of Pisa

Michela Maielli

North-West Tuscany Local Health Authority

Sergio Ardis

University of Pisa, North-West Tuscany Local Health Authority, National Board of the Italian Society for Health Promotion (SIPS)

\section{Publishing Timeline}

Received 16 June 2020

Accepted 28 July 2020

Published 13 August 2020

\section{References}

Adler, A., \& Seligman, M. E. P. (2016). Using wellbeing for public policy: Theory, measurement, and recommendations. International Journal of Wellbeing. https://doi.org/10.5502/ijw.v6i1.429

Ardis, S. (2014). La promozione del benessere. Strumenti per la sua valutazione. (Aonia (ed.)).

Di Fabio, A., Palazzeschi, L., \& Bucci, O. (2017). Gratitude in organizations: A contribution for healthy organizational contexts. Frontiers in Psychology. https://doi.org/10.3389/fpsyg.2017.02025

Diener, E., Suh, E. M., Lucas, R. E., \& Smith, H. L. (1999). Subjective well-being: Three decades of progress. In Psychological Bulletin. https://doi.org/10.1037/0033-2909.125.2.276

Frey, B. S. (2011). Peace, war and happiness: Bruder Klaus as wellbeing facilitator. International Journal of Wellbeing. https://doi.org/10.5502/ijw.v1i2.5

Helliwell, J. F., \& Wang, S. (2011). Trust and Wellbeing. International Journal of Wellbeing. https://doi.org/10.5502/ijw.v1i1.3

Kaplan, S., Bradley-Geist, J. C., Ahmad, A., Anderson, A., Hargrove, A. K., \& Lindsey, A. (2014). A Test of Two Positive Psychology Interventions to Increase Employee Well-Being. Journal of Business and Psychology. https://doi.org/10.1007/s10869-013-9319-4

Kern, M. L., \& Butler, J. (2016). The PERMA-Profiler: A brief multidimensional measure of flourishing. International Journal of Wellbeing. https://doi.org/10.5502/ijw.v6i3.1

Khaw, D., \& Kern, M. L. (2015). A Cross-Cultural Comparison of the PERMA Model of Well-being. Undergraduate Journal of Psychology at Berkeley. https://doi.org/10.1017/CBO9781107415324.004

Luhmann, M., Hofmann, W., Eid, M., \& Lucas, R. E. (2012). Subjective well-being and adaptation to life events: A meta-analysis. Journal of Personality and Social Psychology. https://doi.org/10.1037/a0025948

Montemurro, N. (2020). The emotional impact of COVID-19: From medical staff to common people. Brain, Behavior, and Immunity.

Napier, J. L., \& Jost, J. T. (2008). Why are conservatives happier than liberals? Psychological Science. https://doi.org/10.1111/j.1467-9280.2008.02124.x

Napier, J. L., Thorisdottir, H., \& Jost, J. T. (2010). The joy of sexism? A multinational investigation of 
hostile and benevolent justifications for gender inequality and their relations to subjective wellbeing. Sex Roles. https://doi.org/10.1007/s11199-009-9712-7

OECD Guidelines on Measuring Subjective Well-being. (2013). In OECD Guidelines on Measuring Subjective Well-being. https://doi.org/10.1787/9789264191655-en

Pappa, S., Ntella, V., Giannakas, T., Giannakoulis, V. G., Papoutsi, E., \& Katsaounou, P. (2020). Prevalence of depression, anxiety, and insomnia among healthcare workers during the COVID-19 pandemic: A systematic review and meta-analysis. Brain, Behavior, and Immunity. https://doi.org/10.1016/j.bbi.2020.05.026

Sabatini, F. (2014). The relationship between happiness and health: Evidence from Italy. Social Science and Medicine. https://doi.org/10.1016/j.socscimed.2014.05.024

Schneider, S. M. (2016). Income Inequality and Subjective Wellbeing: Trends, Challenges, and Research Directions. In Journal of Happiness Studies. https://doi.org/10.1007/s10902-015-9655-3

Seligman, M. E. P. (2011). What is Well-Being ? :: Authentic Happiness :: Using the new Positive Psychology. Flourish.

Sheldon, K. M., \& Lyubomirsky, S. (2006). How to increase and sustain positive emotion: The effects of expressing gratitude and visualizing best possible selves. Journal of Positive Psychology. https://doi.org/10.1080/17439760500510676

Stegen, A., \& Wankier, J. (2018). Generating gratitude in the workplace to improve faculty job satisfaction. Journal of Nursing Education. https://doi.org/10.3928/01484834-20180522-10

Stiglitz, J., Fitoussi, J.-P., \& Sen, A. (2009). Rapport de la Commission sur la mesure des performances économiques et du progrès social (extraits). Regards Sur l'actualité.

Watanabe, K., Kawakami, N., Shiotani, T., Adachi, H., Matsumoto, K., Imamura, K., Matsumoto, K., Yamagami, F., Fusejima, A., Muraoka, T., Kagami, T., Shimazu, A., \& Kern, M. L. (2018). The Japanese Workplace PERMA-Profiler: A validation study among Japanese workers. Journal of Occupational Health. https://doi.org/10.1539/joh.2018-0050-OA

Wilson, W. R. (1967). Correlates of avowed happiness. Psychological Bulletin. https://doi.org/10.1037/h0024431

Yuan, S., Liao, Z., Huang, H., Jiang, B., Zhang, X., Wang, Y., \& Zhao, M. (2020). Comparison of the Indicators of Psychological Stress in the Population of Hubei Province and Non-Endemic Provinces in China During Two Weeks During the Coronavirus Disease 2019 (COVID-19) Outbreak in February 2020. Medical Science Monitor : International Medical Journal of Experimental and Clinical Research. https://doi.org/10.12659/MSM.923767 